\title{
A Randomized Trial on Mineralocorticoid Receptor Blockade in Men: Effects on Stress Responses, Selective Attention, and Memory
}

\author{
Sandra Cornelisse ${ }^{*, 1,2}$, Marian Joëls ${ }^{1,2}$ and Tom Smeets ${ }^{3}$ \\ 'Department of Neuroscience and Pharmacology, Rudolf Magnus Institute of Neuroscience, University Medical Center Utrecht, Utrecht, \\ The Netherlands; ${ }^{2}$ SILS-CNS, University of Amsterdam, Amsterdam, The Netherlands; ${ }^{3}$ Department of Psychology and Neuroscience, \\ Maastricht University, Maastricht, The Netherlands
}

\begin{abstract}
Corticosteroids, released in high amounts after stress, exert their effects via two different receptors in the brain: glucocorticoid receptors (GRs) and mineralocorticoid receptors (MRs). GRs have a role in normalizing stress-induced effects and promoting consolidation, while MRs are thought to be important in determining the threshold for activation of the hypothalamic-pituitary-adrenal (HPA) axis. We investigated the effects of MR blockade on HPA axis responses to stress and stress-induced changes in cognitive function. In a doubleblind, placebo-controlled study, 64 healthy young men received $400 \mathrm{mg}$ of the MR antagonist spironolactone or placebo. After I.5 h, they were exposed to either a Trier Social Stress Test or a non-stressful control task. Responses to stress were evaluated by hormonal, subjective, and physiological measurements. Afterwards, selective attention, working memory, and long-term memory performance were assessed. Spironolactone increased basal salivary cortisol levels as well as cortisol levels in response to stress. Furthermore, spironolactone significantly impaired selective attention, but only in the control group. The stress group receiving spironolactone showed impaired working memory performance. By contrast, long-term memory was enhanced in this group. These data support a role of MRs in the regulation of the HPA axis under basal conditions as well as in response to stress. The increased availability of cortisol after spironolactone treatment implies enhanced GR activation, which, in combination with MR blockade, presumably resulted in a decreased MR/GR activation ratio. This condition influences both selective attention and performance in various memory tasks.

Neuropsychopharmacology (20I I) 36, 2720-2728; doi: 10.1038/npp.20I I.162; published online 31 August 20I I
\end{abstract}

Keywords: mineralocorticoid receptor; spironolactone; psychosocial stress; cortisol; memory; selective attention

\section{INTRODUCTION}

Cognitive processes can be affected by stress, both negatively or positively; this applies especially to memory (for reviews, see Lupien et al, 2007; Wolf, 2009). These effects of stress are at least in part due to activation of the hypothalamo-pituitary-adrenal (HPA) axis, resulting in secretion of corticosteroid hormones (mainly cortisol in humans and corticosterone in rodents) from the adrenal gland.

Corticosteroids bind to two types of nuclear receptors, that is, glucocorticoid (GRs) and mineralocorticoid receptors (MRs), which influence brain function primarily by modulating gene transcription (de Kloet et al, 2005; Joels et al, 2006, 2008). MRs and GRs differ in their affinity for

*Correspondence: S Cornelisse, Department of Neuroscience and Pharmacology, Rudolf Magnus Institute of Neuroscience, University Medical Center Utrecht, Universiteitsweg 100, 3584 CG, Utrecht, The Netherlands, Tel: + 3165312 3688, Fax: + 31887569032 ,

E-mail: s.cornelisse-5@umcutrecht.nl

Received 21 February 2011; revised 15 June 201।; accepted 19 July 2011 corticosteroids and are differentially distributed in the brain. GRs are ubiquitously present throughout the brain, have a low affinity for corticosteroids, and mainly have a role when plasma corticosteroid levels are high, that is, after stress (de Kloet et al, 2005; Reul and de Kloet, 1985; Reul et al, 1987). One of the main functions of GRs is to normalize stress-induced effects and promote consolidation, as shown, for example, in rodents (Oitzl et al, 2001; Roozendaal, 2003; Sandi, 1998). MRs are primarily located in limbic areas, which are brain areas critical for cognition and emotion. In the rodent brain, MRs are particularly expressed in the hippocampus (de Kloet et al, 2005; Reul and de Kloet, 1985); in primates, MRs are also found in cortical and subcortical structures (Patel et al, 2000). In contrast to GRs, nuclear MRs have a high affinity for corticosteroids. This leads to extensive MR occupation even when circulating corticosteroid levels are low, that is, under basal conditions. Therefore, the functional significance of the MR in the stress response has been questioned for a long time.

However, recent animal experiments indicate that the MR can also be positioned in the membrane of hippocampal 
neurons, presumably amplifying rapid non-genomic effects by other stress hormones (Karst et al, 2005; Tasker et al, 2006; Joels and Baram, 2009). Importantly, this membranelocated MR appears to have a relatively low affinity for corticosteroids and may therefore respond especially to stress-induced elevations of corticosteroids. In line with this hypothesis, several animal studies recently indicated a role for $M R$ in the early phase of the stress response and in fast effects on cognitive processes (Pace and Spancer, 2005; Khaksari et al, 2007; Schwabe et al, 2010). In humans, however, investigation of this receptor with respect to cognition has so far been very limited (Otte et al, 2007), especially in combination with stress.

Under controlled laboratory conditions, we now investigated the consequences of MR blockade by spironolactone for responses to a psychosocial stressor and cognitive performance. In healthy volunteers, we addressed the following research question: Does MR blockade lead to differences in selective attention, working memory, and long-term memory during a stressful situation, compared with a non-stressful control situation? To validate the effects of spironolactone treatment and stress manipulation, we measured salivary cortisol and $\alpha$-amylase concentrations as well as heart rate and blood pressure throughout the experiment. In previous studies, MR blockade was reported to increase cortisol levels under baseline conditions (Deuschle et al, 1998; Heuser et al, 2000; Young et al, 1998). This situation implies increased binding of available cortisol to GRs. The combination of MR blockade and additional cortisol release by stress will thus presumably lead to a substantial reduction in MR/GR activation ratio, and we hypothesize that this will affect cognition.

\section{MATERIALS AND METHODS}

\section{Participants}

Sixty-four healthy male undergraduate students (mean age $=21.75$ years $(S D=2.68$, ranging from 18 to 26 years); mean body mass index $23.10(\mathrm{SD}=2.72$, ranging from 18 to 30)) were recruited, evaluated, and tested at Maastricht University between July 2009 and December 2009. All participants underwent a screening procedure consisting of a medical and psychiatric history questionnaire (evaluating current lifetime psychiatric diagnosis and medical history, use of medication, alcohol, substance abuse, and smoking), a 12-lead electrocardiogram, laboratory tests (blood biochemistry and hematology, urinalysis, drug screening, serology), and a routine medical examination. Exclusion criteria were cardiovascular disease, severe physical illness, hypertension, hypotension, current or lifetime psychopathology or endocrine disorders, and being on medication known to affect HPA axis functioning. Furthermore, heavy smoking ( $>10$ cigarettes/day), heavy alcohol consumption ( $>60$ g/day), and substance abuse served as exclusion criteria. Before entering the experiment, all subjects signed a written informed consent and were given a monetary reward $(€ 50)$. Participants were instructed to refrain from eating, drinking, heavy exercise, and smoking at least $1 \mathrm{~h}$ before the experimental sessions. All participants reported that they adhered to these instructions. The study was approved by the Medical Ethics Committee of the Academic Hospital Maastricht (CTCM azM, Maastricht, The Netherlands).

\section{Design and Procedure}

We used a randomized, double-blind, placebo-controlled $2 \times 2$ between subjects design. Half of the subjects received $400 \mathrm{mg}$ spironolactone orally, the other half placebo. In both treatment conditions, half of the subjects participated in a stressful task, while the other half was subjected to a nonstressful control task. This resulted in four experimental groups, to which 16 participants were randomly assigned: spironolactone-stress, spironolactone-control, placebostress, and placebo-control. Sample size was determined by power analysis (power $>0.80 ; \alpha=0.05$ ) for detecting medium (Cohen's $d$ ranging from 0.50 to 0.80 ) interaction effects. Spironolactone and placebo pills were provided in sequentially numbered containers by the pharmacy according to a randomization protocol, to which experimenters and participants were blinded until after the study was completed. Recruitment and random assignment to the stress or control task were done by different staff (SC and TS, respectively). The study consisted of two experimental sessions, $24 \mathrm{~h}$ apart. All subjects were tested in the morning between 0800 and 1230 hours, to allow comparison with an earlier study using the same stress paradigm (Smeets et al, 2009). A detailed timeline of the experimental sessions is shown in Figure 1.

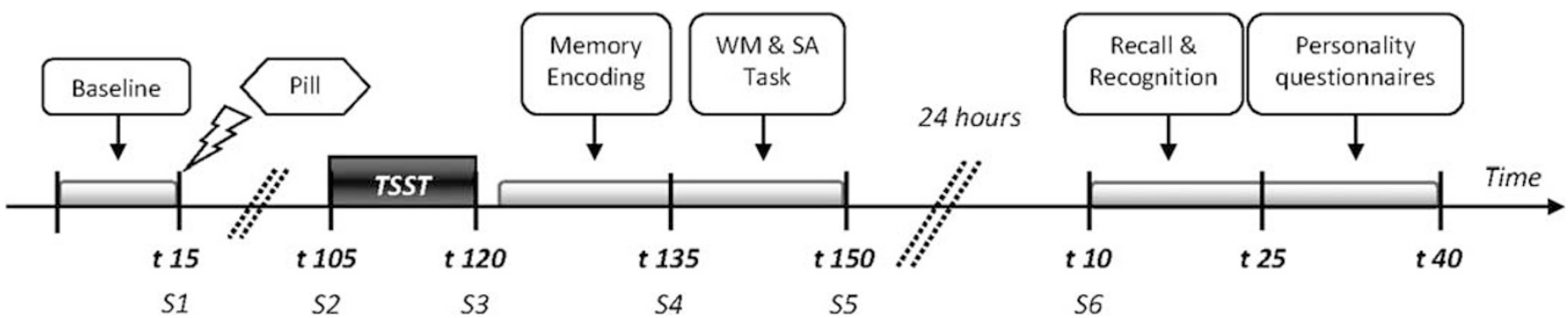

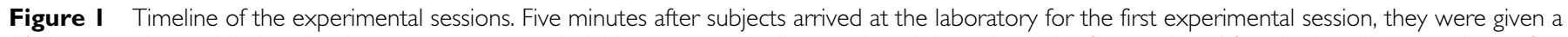

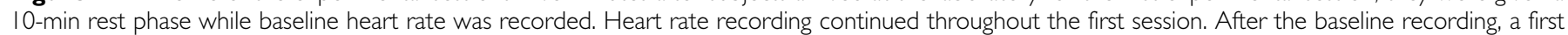

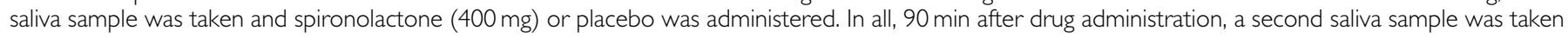

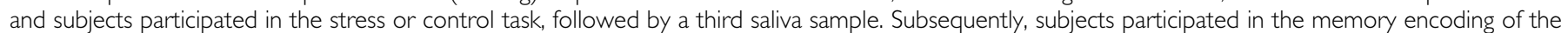

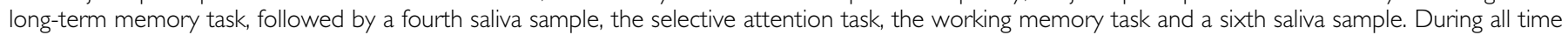

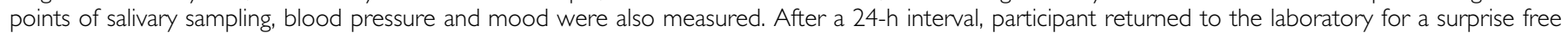
recall and recognition test. 


\section{Stress Manipulation}

The Trier Social Stress Test (TSST) (Kirschbaum et al, 1993) is a valid and reliable procedure to induce neuroendocrine responses. The present study employed a modified TSST (Smeets et al, 2007, 2009) that was more personally relevant and ego threatening, consisting of a 5-min preparation period, a 5-min mental arithmetic task, and a 10-min free speech task. Participants in the stress group were not asked to simulate a job interview, as is typical in the TSST, but instead had to critically describe their own personality characteristics in English (a non-native language) while standing in front of a live audience and being audio- and videotaped.

The control condition consisted of a comparable task, but participants were asked, after a 5-min preparation period, to describe their personality for $10 \mathrm{~min}$ (a free speech task) in an empty room and to perform a simple arithmetic task for $5 \mathrm{~min}$; these tasks were not videotaped and were without an audience (Het et al, 2009).

\section{Salivary Sampling and Biochemical Analysis}

Salivary samples were obtained using Salivette devices (Sarstedt, Etten-Leur, The Netherlands). Samples were stored at $-20{ }^{\circ} \mathrm{C}$ immediately after collection until further analysis. Cortisol levels were measured using a commercially available immunoassay (IBL, Hamburg, Germany). Concentrations of salivary $\alpha$-amylase (sAA) were determined using a commercially available kinetic reaction assay (Salimetrics, Penn State, PA). Levels of sAA are sensitive to changes in adrenergic activation, specifically in reaction to psychological stress (van Stegeren et al, 2006). Determination of sAA levels was therefore here used as an indicator for noradrenergic system activity (in addition to heart rate and blood pressure) during stress manipulation.

\section{Mood Measurements}

Subjects filled out the Positive and Negative Affect Schedule (PANAS) (Watson et al, 1988) during the six saliva sampling time points. The PANAS consists of 10 positive affect and 10 negative affect items to be rated on a 5-point scale, resulting in a separate score for positive and negative affect.

\section{Physiological Measurements}

Heart rate was measured continuously with a sampling rate of $1000 \mathrm{~Hz}$ during the first session of the experiment using portable transmission devices (Polar RS800CX). Blood pressure was measured during the six saliva sampling time points using a fully automated blood pressure monitor (Omron 705IT), with the cuff placed on the right upper arm.

\section{Encoding and Long-Term Memory Task}

During the memory-encoding phase, participants were presented with 24 words (12 personality-related words and 12 personality-unrelated words) (Smeets et al, 2009) from the Affective Norms for English Words (ANEW) (Bradley and Lang, 1999). Words were presented both aurally on a digital voice recorder and visually on a computer screen for three successive learning trials (LT1-3), with participants being explicitly told that their memory for the words would be tested immediately following each learning trial. Subjects were given surprise delayed free recall (DFR) and recognition tests $24 \mathrm{~h}$ later. Following the delayed recall test, participants rated the presented words on arousal. Since no differences were found between personality-related and -unrelated words or based on the arousal ratings, we have only reported the total percentage of recalled words. Misinterpretation of the instructions or obvious lack of motivation was defined a priori as an exclusion criterion for data analysis.

\section{Selective Attention Task}

To assess selective attention, the $\mathrm{d} 2$ test (Brickenkamp, 1978) was used. Stimuli in the $\mathrm{d} 2$ test consist of the letters ' $p$ ' and ' $d$ ' with one, two, three, or four dashes arranged either individually or in pairs above and below the letter. Subjects were instructed to cross out all 'd's' with two dashes. Subsequent to a practice trial, 14 lines of 47 target and distracter stimuli were presented, and the subject had $20 \mathrm{~s}$ to finish each line.

\section{Working Memory Task}

Working memory performance was assessed with an $n$-back task. Subjects were presented with a sequence of one-digit numbers (from 0 to 9), and had to indicate whether the current number matched the number from $n$ trials earlier. Subjects first received a 0-back task, where they had to indicate if the current number was ' 0 ' or not. Subsequently, a total of four experimental blocks varying in task difficulty were given, alternating between 2-back and 3-back tasks. Each block consisted of 24 trials, and the first three blocks were preceded by an instruction screen and six practice trials. The first two trials were excluded from analysis for the 2-back test, and the first three trials were excluded for the 3-back test. Because no differences were found between the two subsequent blocks of the $n$-back task with the same difficulty, we have reported data only for the grouped 2-back and grouped 3-back tasks. Misinterpretation of the instructions or obvious lack of motivation was defined a priori as an exclusion criterion for data analysis.

\section{Statistical Analysis}

All measures that showed a skewed distribution with the Shapiro-Wilk test of normality (cortisol, sAA, and PANAS measurements) were log transformed. Analysis of variance (ANOVA) was then performed on the transformed data. Stress induction measurements during the first session were analyzed using a 5 (time: $\mathrm{t} 15 v s \mathrm{t} 110 v s 130 v s \mathrm{t} 140 v s \mathrm{t} 165)$ $\times 2$ (treatment: spironolactone $v s$ placebo) $\times 2$ (condition: stress $v s$ control) general linear model (GLM) repeated measures ANOVA, where time was a repeated measure. Heart rate was averaged over eight separate periods and analyzed similarly to the other measures, using an eight (time: baseline $v s$ waiting period $v s$ preparation phase TSST $v s$ mental arithmetic task TSST $v s$ free speech TSST $v s$ memory-encoding task $v s$ selective attention task $v s$ 
working memory task) $\times 2$ (treatment) $\times 2$ (condition) GLM repeated measures ANOVA. To investigate cortisol responses to stress in the different groups, the area under the curve increase (AUCi) (Pruessner et al, 2003) was calculated for each subject and analyzed using ANOVA. Selective attention performance was analyzed using 2 (treatment) $\times 2$ (condition) GLM ANOVA. Performance on learning trials and long-term memory was analyzed using a 4 (trial: LT1 vs LT2 vs LT3 vs DFR) $\times 2$ (treatment: spironolactone $v s$ placebo) $\times 2$ (condition: stress $v s$ control) GLM ANOVA with trial as a repeated measure. Working memory was analyzed using a 2 (difficulty: 2-back $v s 3$-back) $\times 2$ (treatment) $\times 2$ (condition) GLM ANOVA, with difficulty being a repeated measure. When sphericity assumptions were violated (Mauchly's test of sphericity), we reported Greenhouse-Geisser corrected $p$-values. If there were significant interaction effects (time $\times$ condition interactions to assess stress responses and trial/block $\times$ treatment $\times$ condition interactions to assess drug and stress effects), planned comparisons were performed. In there were post hoc analyses, data in all cases were corrected with Tukey's HSD test for multiple comparisons.

\section{RESULTS}

\section{Participants}

The four experimental groups did not differ in terms of age, body mass index, or education (in all cases $p>0.15$ ).

There were no adverse effects from spironolactone administration. All participants completed both sessions, and there were no missing data. One subject (from the placebo-stress group) was excluded from all analyses due to extremely high cortisol levels throughout the experiment. Three additional subjects were excluded from the long-term and working memory analyses because they had not understood the task instructions correctly (an a priori exclusion criterion) and thus performed very poorly ( $>2$ $\mathrm{SD}$ below the group mean).

\section{Stress Responses}

The experimental groups did not differ on any of the measured baseline variables (cortisol, $\alpha$-amylase, blood pressure, heart rate, and PANAS; all $p$-values $>0.30$; see Figure 2 and Supplementary Tables 1 and 2). As expected, the ANOVA for cortisol showed a significant time $\times$ condition interaction $(\mathrm{F}(2,131)=19.26, p<0.001)$ (Figure 2). Planned simple contrasts related to baseline showed that subjects in the stress condition had increased cortisol levels from $20 \mathrm{~min}$ after the start of stress induction (S3) until the end of the first session $(S 4, S 5)$, compared with control subjects (all $p$-values $<0.001$ ). Furthermore, a significant time $\times$ treatment interaction $(\mathrm{F}(2,131)=6.79, p=0.001)$ (Figure 2) was found; post hoc simple contrasts indicated overall increased cortisol levels after spironolactone treatment $(S 2-S 5$; all $p$-values $<0.005)$ compared with baseline. Except for a significant main effect of time $(\mathrm{F}(2,131)=19.44, p<0.001)$, no other significant main or interactive effects were found. Interestingly, our results showed that within the stress group, cortisol responses (AUCi) were significantly increased after spironolactone

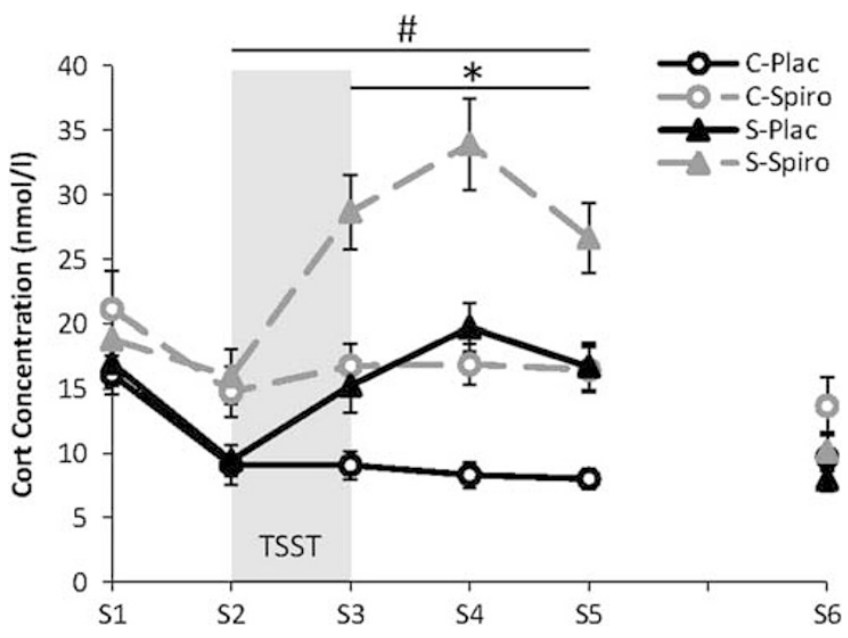

Figure 2 Effects of psychosocial stress and spironolactone treatment on salivary cortisol levels. The conducted ANOVA revealed significant time $\times$ condition and time $\times$ treatment interaction effects. Post hoc tests condition: ${ }^{*} p<0.05$, treatment: ${ }^{*} p<0.05$.

treatment (mean \pm SD: $572.2 \pm 91.9$ ) compared with placebo treatment (mean \pm SD: $\quad 310.5 \pm 40.7 ; \quad \mathrm{F}(1,29)=6.48$, $p=0.017)$. Within the control group, cortisol responses (AUCi) after spironolactone (mean \pm SD: $80.3 \pm 49.4$ ) and placebo treatment (mean \pm SD: $-21.3 \pm 41.5$ ) did not differ $(p>0.10)$.

For $\alpha$-amylase, a significant time $\times$ condition interaction $(\mathrm{F}(3,154)=5.40, p=0.002)$ and a significant main effect of time $(\mathrm{F}(3,154)=30.51, p<0.001)$ were found (Supplementary Table 1). Planned simple contrasts compared with baseline showed that $\alpha$-amylase levels were increased in the stress condition only at the time point immediately after the TSST ( 3 ; $p=0.008)$, compared with the control condition. The ANOVA for subjective negative affect state also yielded a significant time $\times$ condition interaction $(\mathrm{F}(4,236)=21.25, p=0.002)$ and a significant main effect of time $(\mathrm{F}(4,236)=11.34, p<0.001)$ (Supplementary Table 1). Planned simple contrasts related to baseline showed increased negative affect in subjects in the stress condition only immediately after the TSST $(S 3 ; p<0.001)$, compared with control subjects. For positive affect, no significant effects of condition were found. Likewise, both systolic (time $\times$ condition: $\mathrm{F}(3,204)=19.92, \quad p<0.001$; time: $\mathrm{F}(3,204)=12.22, p<0.001)$ and diastolic blood pressure (time $\times$ condition: $\mathrm{F}(4,236)=6.55, \quad p<0.001$; time: $\mathrm{F}(4,236)=19.21, p<0.001)$ increased in the stress group compared with the control group immediately after the stress task ( $S 3 ; p$-values $<0.01$; Supplementary Table 1$)$. Finally, for heart rate, the ANOVA also showed a significant time $\times$ condition interaction $(\mathrm{F}(5,292)=17.49, p<0.001)$ and a significant main effect of time $(F(5,292)=17.91$, $p<0.001$ ) (Supplementary Table 2). Planned simple contrasts compared with baseline showed elevated heart rate in the stress group compared with the control group during the entire TSST, including preparation period, mental arithmetic task, and free speech $(S 2-S 3$; $p$-values $<0.001)$, but not during further testing. Spironolactone treatment did not affect $\alpha$-amylase, PANAS, blood pressure, or heart rate measurements. 


\section{Learning Performance and Long-Term Memory}

Figure 3 depicts the percentages of correctly recalled words on learning trials and DFR. A significant interaction between trial, treatment, and condition was found $(\mathrm{F}(2,134)=3.00$, $p=0.046)$. Since we expected this effect to be especially due to the delayed trial, we conducted planned comparisons for DFR performance, which showed a significant treatment $\times$ condition interaction effect $(\mathrm{F}(1,56)=5.81, p=0.019)$ and a significant main effect of condition $(F(1,56)=5.46$, $p=0.023)$. On the three learning trials, however, no significant main or interactive effects involving treatment and condition were found ( $p$-values $>0.20)$. Post hoc Tukey's multiple comparisons revealed that subjects in the stress condition receiving spironolactone recalled significantly more words than the control-spironolactone group $(p=0.008)$ and tended to perform better compared with the other two groups $(p=0.10)$, while no differences were found between all other groups ( $p$-values $>0.70)$. No effects of either treatment or condition were found on delayed recognition performance.

\section{Selective Attention}

Performance on the $\mathrm{d} 2$ task, as measured by the percentage of correctly processed items, was significantly impaired after spironolactone compared with placebo treatment $(\mathrm{F}(1,59)=4.36, p=0.041$; Table 1$)$. Separate analyses for the effect of treatment in both the stress group and the

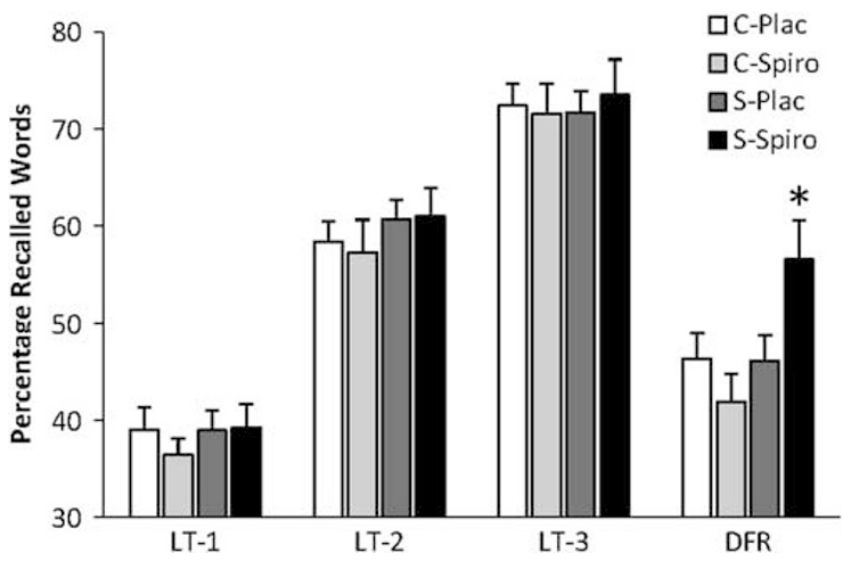

Figure 3 Percentage of correct recall of words at learning trials and DFR. No differences between groups were found on the learning trials, but at DFR subjects in the Stress condition that received spironolactone recalled significantly more words compared with all other groups. $* p<0.05$ in planned comparisons.

Table I Mean (SEM) Performance and Error Rates on the d2 Selective Attention Task

\begin{tabular}{lcccc}
\hline & C-Plac & C-Spiro & S-Plac & S-Spiro \\
\hline $\mathrm{d} 2 \%$ Correctly processed & $75.10(13.06)$ & $65.07(10.96) *$ & $69.77(12.33)$ & $69.29(12.25)$ \\
$\mathrm{d} 2 \%$ Errors of omission & $3.04(2.68)$ & $3.64(2.50)$ & $3.48(2.94)$ & $3.59(2.13)$ \\
$\mathrm{d} 2 \%$ Errors of commission & $0.17(0.19)$ & $0.25(0.44)$ & $0.50(0.58)^{*}$ & $0.26(0.33)$ \\
\hline
\end{tabular}

${ }^{*} p<0.05$ against the control-placebo group. control group revealed a significant selective attention impairment after spironolactone treatment within the control group $(\mathrm{F}(1,30)=5.54, p=0.025)$ but not within the stress group $(p>0.50)$. Furthermore, stress tended to increase the percentage of commission errors during the selective attention task $(F(1,59)=3.52, p=0.066)$. Separate analyses showed that this effect was only apparent under placebo conditions $(\mathrm{F}(1,29)=4.44, p=0.045)$, but not after spironolactone treatment $(p>0.50)$.

\section{Working Memory}

No differences between groups were observed in the percentage of correct responses or in reaction times on the 0 -back task ( $p$-values $>0.3$ ). The ANOVA for percentage correct responses revealed a significant interaction effect between difficulty, treatment, and condition $(\mathrm{F}(1,56)=5.34$, $p=0.024$; see Figure 4 ) and a main effect of difficulty $(\mathrm{F}(1,56)=65.77, p<0.001)$. Subjects performed better on the 2-back than on the 3-back task. To further explore the interaction effect, separate ANOVAs for both difficulties showed that there was a significant treatment $\times$ condition interaction only for the 2-back task $(\mathrm{F}(1,56)=4.64$, $p=0.036)$ and not for the 3 -back task $(p>0.50)$. Followup post hoc Tukey's multiple comparison of the means revealed that within the stress group, performance on the 2-back task was impaired after spironolactone treatment $(\mathrm{F}(1,27)=7.18, p=0.012)$, while no differences were found within the control group $(p>0.50)$. Regarding reaction times, only a main effect of difficulty $(F(1,56)=20.04$, $p<0.001)$ was found; subjects responded faster on the 2-back compared with the 3-back task.

\section{DISCUSSION}

Our study shows that MR blockade in humans leads to impaired selective attention during a non-stressful situation, while working memory and long-term memory are differentially affected by the combination of MR blockade and stress.

In line with earlier studies (Deuschle et al, 1998; Heuser et al, 2000; Young et al, 1998), we found significantly higher

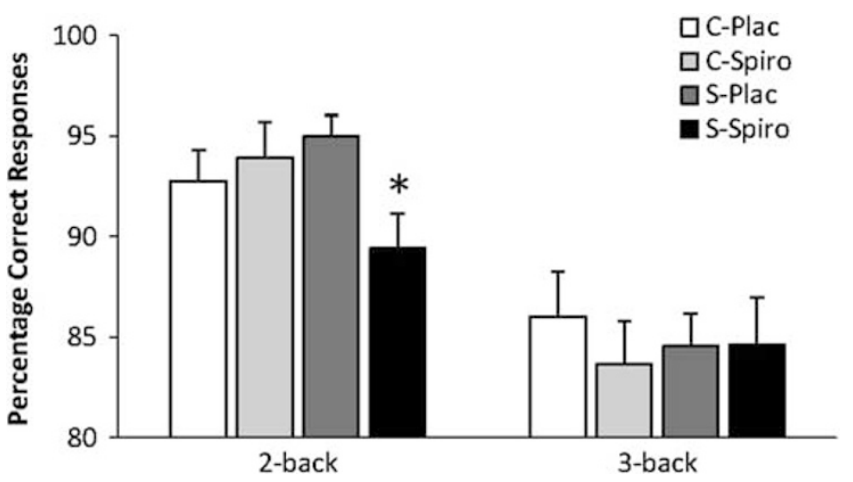

Figure 4 Performance (percentage of correct responses) on the working memory task. The ANOVA revealed a significant difficulty $\times$ treatment $\times$ condition effect; subjects in the Stress condition that received spironolactone performed significantly better on the 2-back task compared with all other groups. ${ }^{*} p<0.05$ in planned comparisons. 
basal cortisol levels after spironolactone administration. Although MR blockade was previously reported to increase cortisol levels during rest at both the peak and the trough of the circadian rhythm (Young et al, 1998) as well as during physical exercise (Wellhoener et al, 2004) and in response to dexamethasone suppression/corticotrophin releasing hormone stimulation (Berardelli et al, 2010; Heuser et al, 2000), its effect on psychosocial stress responses was unknown. We can now report that cortisol responses to psychosocial stress are increased after spironolactone compared with placebo treatment. These results lend further support to the assumption that MRs have a role in human HPA axis regulation (Deuschle et al, 1998; Heuser et al, 2000; Otte et al, 2007; Young et al, 1998), not only under baseline conditions, but also in stressful situations. Subjective responses to stress (specifically in the group exposed to a TSST) were unaffected by MR blockade. Furthermore, none of the parameters reflecting sympathetic activity, such as sAA levels, blood pressure, or heart rate, were affected by spironolactone. Taken together, these findings suggest that the MR antagonist disinhibited the HPA axis, but did not influence the other major stress system assessed in this study.

Chronic spironolactone administration is used as a treatment for hypertension and leads to a decrease in blood pressure (Batterink et al, 2010). We found that a single oral administration of spironolactone does not change blood pressure in humans, which replicated a similar finding by Otte et al (2007). This finding is to some extent at odds with rodent studies, which reported a reduction in blood pressure in response to acute MR antagonism (van den Berg et al, 1990; Rahmouni et al, 2002). However, it should be noted that the latter reduction peaked at $8 \mathrm{~h}$ after administration and was only observed after intracerebroventricular, but not subcutaneous, delivery of the antagonist. Therefore, differences in species, post-administration delay, delivery route, and possibly the administered dose may explain the observed discrepancies.

Subjects were behaviorally tested under variable conditions of circulating hormone levels and MR activation patterns. In all spironolactone-treated individuals, $\mathrm{MR}$ activation was presumably low due to the antagonistic properties of the drug. Moreover, in view of the raised cortisol levels, GR activation was assumed to be enhanced. This presumed shift in MR toward GR activation was expected to be most prominent in spironolactone-treated individuals of the stress group, showing the highest circulating cortisol levels while MRs were blocked. Since cortisol levels were elevated at all time points after stress exposure, this condition most likely was present during all behavioral tasks. Obviously, to unravel the specific roles of MRs, GRs and the MR/GR activation balance, more studies with selective MR and GR (ant)agonists will be necessary. Indices of sympathetic activation (eg, $\alpha$-amylase, blood pressure, and heart rate) were only briefly affected after stress, that is, during the very first phase of the cognitive tasks. These indices could therefore have had a role during encoding of the verbal memory test, but most likely not during the selective attention and $n$-back tasks. Furthermore stress, but not spironolactone, induced short-lived increases in negative affect.
We replicated the finding of Otte et al (2007) that MR blockade by spironolactone impairs selective attention under non-stressful conditions. This was not observed after stress, which might indicate that MR activation promotes selective attention, an effect that possibly could be counteracted by GR activation. Working memory was reduced by spironolactone, but only when subjects were also exposed to stress. This suggests that extensive MR blockade in combination with high cortisol levels, probably leading to increased GR binding, impairs working memory. It should be noted that we did not selectively activate GRs and that the degree to which this receptor type was activated during the behavioral tests was only inferred from circulating hormone levels, so this remains speculative. However, our interpretation is supported by a study in Addison's patients who were selectively treated with MR and/or GR agonists (Tytherleigh et al, 2004). Comparable to our findings, this study showed that selective GR agonists (and hence a low MR/GR activation ratio) resulted in impaired working memory performance compared with treatment with both MR and GR agonists (cf. our placebo-control condition). Apparently, activation of specific adrenergic receptors (Barch, 2004; Chamberlain et al, 2006; Ramos and Arnsten, 2007) as well as MR and GR activation each affect working memory in a different way, so that the exact time at which working memory is tested relative to stress exposure is important for the outcome. Also, the time of the day, the nature of the stressor and the memory tasks, the time spent in the laboratory before the stressor and possible interference with other tasks during the study can influence the direction of stress effects on memory. This may explain why some studies reported working memory to be decreased by stress (Elzinga and Roelofs, 2005; Luethi et al, 2008; Oei et al, 2006; Schoofs et al, 2008, 2009) whereas others observed increased function (Cornelisse et al, 2011; Duncko et al, 2009; Kuhlmann et al, 2005; Oei et al, 2009; Weerda et al, 2010). The current observations clearly indicate that when subjects are tested under conditions of MR blockade - which arguably might shift the balance from MR activation toward GR activation - working memory is impaired.

Interpretation of the data on the verbal long-term memory task in terms of receptor activation is multifaceted. During the learning process, occurring shortly after the stressor, both sAA and cortisol levels were enhanced, the latter particularly in the spironolactone-treated group. In this group, adrenergic activation was coupled to minimal MR activation and presumably extensive GR activation. This reduction of MR relative to GR activation most likely persisted during the consolidation phase, while adrenergic activation at that time was supposedly low again. Long-term memory was improved by the combination of stress and spironolactone treatment, in the absence of any effect on learning. This would fit with the notion, based on animal studies, that GRs have an important role in memory consolidation (Roozendaal, 2003; Sandi, 1998). Thus, memory-modulating effects of corticosteroids selectively involve GR activation (Oitzl and de Kloet, 1992; Sandi and Rose, 1994), requiring DNA binding of GR homodimers (Oitzl et al, 2001), and involving interactions with other systems, like noradrenergic activation in the amygdala (Roozendaal et al, 1999, 2003; Roozendaal and McGaugh, 1997). To find out whether these behavioral effects in 
animals can be directly related to the observed increases in salivary cortisol in humans would require more investigation. Since corticosteroids might be locally synthesized and released in the hippocampus and other brain regions (see McManus et al, 2009), it cannot be excluded that behavioral effects of spironolactone are mediated through disruption of central mineralocorticoid circuits.

Notably, stress did not affect long-term memory and working memory under placebo conditions. This confirms earlier findings under identical test conditions showing no effect of stress on the overall number of words remembered (Smeets et al, 2009). In that study, individual arousal ratings were binomially distributed, allowing separate analysis of high- $v s$ low-arousing words. Stress was reported to enhance learning and memory of high-arousing context-related words, at the cost of low-arousing context-related words, while no such difference was observed for context-unrelated words (Smeets et al, 2009). In the current study, however, the distribution was not binomial, and ratings varied little within subjects. Unfortunately, this precluded further analysis of stress effects on subgroups of words. Another limitation of the current study was that we did not address the relevance of gender or age. Furthermore, it would be interesting to investigate the effects of stress and MR blockade on other hippocampus-dependent tasks like visuo-spatial memory.

Evidence suggests that cortisol resistance and elevated cortisol levels are associated with major depression, rendering the HPA axis a plausible target for novel antidepressant medication (Adam et al, 2008; Holsboer, 2001). Corticosteroids receptors have also been implicated in the pathogenesis of depression (de Kloet et al, 2007; Young et al, 2003). Several MR and GR gene variants were found in association with psychopathology and responsiveness to antidepressants, as well as with altered cognitive performance (Derijk and de Kloet, 2008; Klok et al, 2010; Kuningas et al, 2007; Spijker and van Rossum, 2009). Furthermore, it has been proposed that reduced functionality of MRs relative to GRs may predispose to depression (de Kloet et al, 2005; Reul et al, 2000), while antidepressants might restore the balance between the two receptor types (Bjartmar et al, 2000; Mason and Pariante, 2006; Reul et al, 1993; Seckl and Fink, 1992). Additional support for a role of MR in depression comes from data showing that an MR antagonist inhibits the clinical efficacy of antidepressant treatment (Holsboer, 1999), from a study showing acceleration of antidepressant effects through MR stimulation (Otte et al, 2010) and indications for MR dysfunction in treatment-resistant depression (Juruena et al, 2010). Thus, our current observations with spironolactone treatmentwhich presumably decrease the MR/GR activation ratiomight help to gain more insight into cognitive processes involved in the etiology of major depression. Indeed, $n$-back deficits were observed in major depression (Harvey et al, 2004; Rose and Ebmeier, 2006), and even proposed as diagnostic predictor with highest diagnostic classification at the mid-level of task difficulty (2-back) (Marquand et al, 2008), very similar to our finding after MR blockade. In case of the patients suffering from depression, though, this deficit may be compensated by a significant increase in the load-response activity of cortical regions (Harvey et al, 2005; Mannie et al, 2010; Matsuo et al, 2007). The latter illustrates that comparison of experimentally induced acute MR blockade with conditions that probably developed gradually, as in major depression, should be cautiously interpreted.

\section{ACKNOWLEDGEMENTS}

This work was supported in part by Grant 451-08-005 from the Netherlands Organization for Scientific Research (NWO) to Dr Tom Smeets. We thank Cees van Leeuwen for medical supervision and screening of the participants.

\section{DISCLOSURE}

The authors declare no conflict of interest.

\section{REFERENCES}

Adam EK, Sutton JM, Doane LD, Mineka S (2008). Incorporating hypothalamic-pituitary-adrenal axis measures into preventive interventions for adolescent depression: are we there yet? Dev Psychopathol 20: 975-1001.

Barch DM (2004). Pharmacological manipulation of human working memory. Psychopharmacology (Berl) 174: 126-135.

Batterink J, Stabler SN, Tejani AM, Fowkes CT (2010). Spironolactone for hypertension. Cochrane Database Syst Rev, CD008169.

Berardelli R, Karamouzis I, Marinazzo E, Prats E, Picu A, Giordano $\mathrm{R}$ et al (2010). Effect of acute and prolonged mineralocorticoid receptor blockade on spontaneous and stimulated hypothalamic-pituitary-adrenal axis in humans. Eur J Endocrinol 162: 1067-1074.

Bjartmar L, Johansson IM, Marcusson J, Ross SB, Seckl JR, Olsson T (2000). Selective effects on NGFI-A, MR, GR and NGFI-B hippocampal mRNA expression after chronic treatment with different subclasses of antidepressants in the rat. Psychopharmacology (Berl) 151: 7-12.

Bradley MM, Lang PJ (1999). Affective norms for English words (ANEW): Instruction manual and affective ratings. The Center for Research in Psychophysiology. University of Florida: Gainesville, FL.

Brickenkamp R (1978). Test $d 2$. Handanweisung [Test $d 2$. Manual]. Hogrefe: Gottingen (Germany).

Chamberlain SR, Muller U, Blackwell AD, Robbins TW, Sahakian BJ (2006). Noradrenergic modulation of working memory and emotional memory in humans. Psychopharmacology (Berl) 188: 397-407.

Cornelisse S, van Stegeren AH, Joels M (2011). Implications of psychosocial stress on memory formation in a typical male versus female student sample. Psychoneuroendocrinology 36: 569-578.

de Kloet ER, Derijk RH, Meijer OC (2007). Therapy insight: is there an imbalanced response of mineralocorticoid and glucocorticoid receptors in depression? Nat Clin Pract Endocrinol Metab 3: 168-179.

de Kloet ER, Joels M, Holsboer F (2005). Stress and the brain: from adaptation to disease. Nat Rev Neurosci 6: 463-475.

Derijk RH, de Kloet ER (2008). Corticosteroid receptor polymorphisms: determinants of vulnerability and resilience. Eur $J$ Pharmacol 583: 303-311.

Deuschle M, Weber B, Colla M, Muller M, Kniest A, Heuser I (1998). Mineralocorticoid receptor also modulates basal activity of hypothalamus-pituitary-adrenocortical system in humans. Neuroendocrinology 68: 355-360. 
Duncko R, Johnson L, Merikangas K, Grillon C (2009). Working memory performance after acute exposure to the cold pressor stress in healthy volunteers. Neurobiol Learn Mem 91: 377-381.

Elzinga BM, Roelofs K (2005). Cortisol-induced impairments of working memory require acute sympathetic activation. Behav Neurosci 119: 98-103.

Harvey PO, Fossati P, Pochon JB, Levy R, Lebastard G, Lehericy S et al (2005). Cognitive control and brain resources in major depression: an fMRI study using the n-back task. Neuroimage 26: 860-869.

Harvey PO, Le Bastard G, Pochon JB, Levy R, Allilaire JF, Dubois B et al (2004). Executive functions and updating of the contents of working memory in unipolar depression. J Psychiatr Res 38: $567-576$

Het S, Rohleder N, Schoofs D, Kirschbaum C, Wolf OT (2009). Neuroendocrine and psychometric evaluation of a placebo version of the 'Trier Social Stress Test'. Psychoneuroendocrinology 34: 1075-1086.

Heuser I, Deuschle M, Weber B, Stalla GK, Holsboer F (2000). Increased activity of the hypothalamus-pituitary-adrenal system after treatment with the mineralocorticoid receptor antagonist spironolactone. Psychoneuroendocrinology 25: 513-518.

Holsboer F (1999). The rationale for corticotropin-releasing hormone receptor (CRH-R) antagonists to treat depression and anxiety. J Psychiatr Res 33: 181-214.

Holsboer F (2001). Stress, hypercortisolism and corticosteroid receptors in depression: implications for therapy. J Affect Disord 62: 77-91.

Joels M, Baram TZ (2009). The neuro-symphony of stress. Nat Rev Neurosci 10: 459-466.

Joels M, Karst H, DeRijk R, de Kloet ER (2008). The coming out of the brain mineralocorticoid receptor. Trends Neurosci 31: 1-7.

Joels M, Pu Z, Wiegert O, Oitzl MS, Krugers HJ (2006). Learning under stress: how does it work? Trends Cogn Sci 10: 152-158.

Juruena MF, Cleare AJ, Papadopoulos AS, Poon L, Lightman S, Pariante CM (2010). The prednisolone suppression test in depression: dose-response and changes with antidepressant treatment. Psychoneuroendocrinology 35: 1486-1491.

Karst H, Berger S, Turiault M, Tronche F, Scutz G, Joels M (2005). Mineralocorticoid receptors are indispensable for nongenomlc modulation of hippocampal glutamate transmission by corticosterone. Proc Natl Acad Sci USA 102: 19204-19207.

Khaksari M, Rashidy-Pour A, Vafaei AA (2007). Central mineralocorticoid receptors are indispensable for corticosteroneinduced impairment of memory retrieval in rats. Neuroscience 149: $729-738$

Kirschbaum C, Pirke KM, Hellhammer DH (1993). The 'Trier Social Stress Test' - a tool for investigating psychobiological stress responses in a laboratory setting. Neuropsychobiology 28: 76-81.

Klok MD, Vreeburg SA, Penninx BW, Zitman FG, de Kloet ER, Derijk RH (2010). Common functional mineralocorticoid receptor polymorphisms modulate the cortisol awakening response: interaction with SSRIs. Psychoneuroendocrinology 36: 484-494.

Kuhlmann S, Piel M, Wolf OT (2005). Impaired memory retrieval after psychosocial stress in healthy young men. J Neurosci 25: 2977-2982.

Kuningas M, de Rijk RH, Westendorp RG, Jolles J, Slagboom PE, van Heemst D (2007). Mental performance in old age dependent on cortisol and genetic variance in the mineralocorticoid and glucocorticoid receptors. Neuropsychopharmacology 32: $1295-1301$.

Luethi M, Meier B, Sandi C (2008). Stress effects on working memory, explicit memory, and implicit memory for neutral and emotional stimuli in healthy men. Front Behav Neurosci 2: 5.

Lupien SJ, Maheu F, Tu M, Fiocco A, Schramek TE (2007). The effects of stress and stress hormones on human cognition: Implications for the field of brain and cognition. Brain Cogn 65: 209-237.
Mannie ZN, Harmer CJ, Cowen PJ, Norbury R (2010). A functional magnetic resonance imaging study of verbal working memory in young people at increased familial risk of depression. Biol Psychiatry 67: 471-477.

Marquand AF, Mourao-Miranda J, Brammer MJ, Cleare AJ, Fu CH (2008). Neuroanatomy of verbal working memory as a diagnostic biomarker for depression. Neuroreport 19: 1507-1511.

Mason BL, Pariante CM (2006). The effects of antidepressants on the hypothalamic-pituitary-adrenal axis. Drug News Perspect 19: 603-608.

Matsuo K, Glahn DC, Peluso MA, Hatch JP, Monkul ES, Najt P et al (2007). Prefrontal hyperactivation during working memory task in untreated individuals with major depressive disorder. Mol Psychiatry 12: 158-166.

McManus F, MacKenzie SM, Freel EM (2009). Central mineralocorticoid receptors, sympathetic activity, and hypertension. Curr Hypertens Rep 11: 224-230.

Oei NY, Everaerd WT, Elzinga BM, van Well S, Bermond B (2006). Psychosocial stress impairs working memory at high loads: an association with cortisol levels and memory retrieval. Stress 9: 133-141.

Oei NY, Tollenaar MS, Spinhoven P, Elzinga BM (2009). Hydrocortisone reduces emotional distracter interference in working memory. Psychoneuroendocrinology 34: 1284-1293.

Oitzl MS, de Kloet ER (1992). Selective corticosteroid antagonists modulate specific aspects of spatial orientation learning. Behav Neurosci 106: 62-71.

Oitzl MS, Reichardt HM, Joels M, de Kloet ER (2001). Point mutation in the mouse glucocorticoid receptor preventing DNA binding impairs spatial memory. Proc Natl Acad Sci U S A 98: 12790-12795.

Otte C, Hinkelmann K, Moritz S, Yassouridis A, Jahn H, Wiedemann $\mathrm{K}$ et al (2010). Modulation of the mineralocorticoid receptor as add-on treatment in depression: a randomized, double-blind, placebo-controlled proof-of-concept study. J Psychiatr Res 44: 339-346.

Otte C, Moritz S, Yassouridis A, Koop M, Madrischewski AM, Wiedemann $\mathrm{K}$ et al (2007). Blockade of the mineralocorticoid receptor in healthy men: effects on experimentally induced panic symptoms, stress hormones, and cognition. Neuropsychopharmacology 32: 232-238.

Pace TW, Spencer RL (2005). Disruption of mineralocorticoid receptor function increases corticosterone responding to a mild, but not moderate, psychological stressor. Am J PhysioI Metab 288: E1082-1088.

Patel PD, Lopez JF, Lyons DM, Burke S, Wallace M, Schatzberg AF (2000). Glucocorticoid and mineralocorticoid receptor mRNA expression in squirrel monkey brain. J Psychiatr Res 34: 383-392.

Pruessner JC, Kirschbaum C, Meinlschmid G, Hellhammer DH (2003). Two formulas for computation of the area under the curve represent measures of total hormone concentration versus time-dependent change. Psychoneuroendocrinology 28: 916-931.

Rahmouni K, Sibug RM, De Kloet ER, Barthelmebs M, Grima M, Imbs JL et al. (2002). Effects of brain mineralocorticoid receptor blockade on blood pressure and renal functions in DOCA-salt hypertension. Eur J Pharmacol 436: 207-216.

Ramos BP, Arnsten AF (2007). Adrenergic pharmacology and cognition: focus on the prefrontal cortex. Pharmacol Ther 113: 523-536.

Reul JM, de Kloet ER (1985). Two receptor systems for corticosterone in rat brain: microdistribution and differential occupation. Endocrinology 117: 2505-2511.

Reul JM, Gesing A, Droste S, Stec IS, Weber A, Bachmann C et al (2000). The brain mineralocorticoid receptor: greedy for ligand, mysterious in function. Eur J Pharmacol 405: 235-249.

Reul JM, Stec I, Soder M, Holsboer F (1993). Chronic treatment of rats with the antidepressant amitriptyline attenuates the 
activity of the hypothalamic-pituitary-adrenocortical system. Endocrinology 133: 312-320.

Reul JM, van den Bosch FR, de Kloet ER (1987). Differential response of type I and type II corticosteroid receptors to changes in plasma steroid level and circadian rhythmicity. Neuroendocrinology 45: 407-412.

Roozendaal B (2003). Systems mediating acute glucocorticoid effects on memory consolidation and retrieval. Prog Neuropsychopharmacol Biol Psychiatry 27: 1213-1223.

Roozendaal B, Griffith QK, Buranday J, De Quervain DJ, McGaugh JL (2003). The hippocampus mediates glucocorticoid-induced impairment of spatial memory retrieval: dependence on the basolateral amygdala. Proc Natl Acad Sci U S A 100: 1328-1333.

Roozendaal B, McGaugh JL (1997). Basolateral amygdala lesions block the memory-enhancing effect of glucocorticoid administration in the dorsal hippocampus of rats. Eur J Neurosci 9: $76-83$

Roozendaal B, Nguyen BT, Power AE, McGaugh JL (1999). Basolateral amygdala noradrenergic influence enables enhancement of memory consolidation induced by hippocampal glucocorticoid receptor activation. Proc Natl Acad Sci U S A 96: 11642-11647.

Rose EJ, Ebmeier KP (2006). Pattern of impaired working memory during major depression. J Affect Disord 90: 149-161.

Sandi C (1998). The role and mechanisms of action of glucocorticoid involvement in memory storage. Neural Plast 6: 41-52.

Sandi C, Rose SP (1994). Corticosteroid receptor antagonists are amnestic for passive avoidance learning in day-old chicks. Eur $J$ Neurosci 6: 1292-1297.

Schoofs D, Preuss D, Wolf OT (2008). Psychosocial stress induces working memory impairments in an n-back paradigm. Psychoneuroendocrinology 33: 643-653.

Schoofs D, Wolf OT, Smeets T (2009). Cold pressor stress impairs performance on working memory tasks requiring executive functions in healthy young men. Behav Neurosci 123: 1066-1075.

Schwabe L, Schächinger H, de Kloet ER, Oitzl MS (2010). Corticosteroids operate as a switch between memory systems. J Cogn Neurosci 22: 1362-1372.

Seckl JR, Fink G (1992). Antidepressants increase glucocorticoid and mineralocorticoid receptor mRNA expression in rat hippocampus in vivo. Neuroendocrinology 55: 621-626.
Smeets T, Giesbrecht T, Jelicic M, Merckelbach H (2007). Contextdependent enhancement of declarative memory performance following acute psychosocial stress. Biol Psychol 76: 116-123.

Smeets T, Wolf OT, Giesbrecht T, Sijstermans K, Telgen S, Joels M (2009). Stress selectively and lastingly promotes learning of context-related high arousing information. Psychoneuroendocrinology 34: 1152-1161.

Spijker AT, van Rossum EF (2009). Glucocorticoid receptor polymorphisms in major depression. Focus on glucocorticoid sensitivity and neurocognitive functioning. Ann NY Acad Sci 1179: $199-215$.

Tasker JG, Di S, Malcher-Lopes R (2006). Minireview: rapid glucocorticoid signaling via membrane-associated receptors. Endocrinology 147: 5549-5556.

Tytherleigh MY, Vedhara K, Lightman SL (2004). Mineralocorticoid and glucocorticoid receptors and their differential effects on memory performance in people with Addison's disease. Psychoneuroendocrinology 29: 712-723.

van den Berg DT, de Kloet ER, van Dijken HH, de Jong W (1990). Differential central effects of mineralocorticoid and glucocorticoid agonists and antagonists on blood pressure. Endocrinology 126: $118-124$.

van Stegeren A, Rohleder N, Everaerd W, Wolf OT (2006). Salivary alpha amylase as marker for adrenergic activity during stress: effect of betablockade. Psychoneuroendocrinology 31: 137-141.

Watson D, Clark LA, Tellegen A (1988). Development and validation of brief measures of positive and negative affect: the PANAS scales. J Pers Soc Psychol 54: 1063-1070.

Weerda R, Muehlhan M, Wolf OT, Thiel CM (2010). Effects of acute psychosocial stress on working memory related brain activity in men. Hum Brain Mapp 31: 1418-1429.

Wellhoener P, Born J, Fehm HL, Dodt C (2004). Elevated resting and exercise-induced cortisol levels after mineralocorticoid receptor blockade with canrenoate in healthy humans. J Clin Endocrinol Metab 89: 5048-5052.

Wolf OT (2009). Stress and memory in humans: twelve years of progress? Brain Res 1293: 142-154.

Young EA, Lopez JF, Murphy-Weinberg V, Watson SJ, Akil H (1998). The role of mineralocorticoid receptors in hypothalamicpituitary-adrenal axis regulation in humans. J Clin Endocrinol Metab 83: 3339-3345.

Young EA, Lopez JF, Murphy-Weinberg V, Watson SJ, Akil H (2003). Mineralocorticoid receptor function in major depression. Arch Gen Psychiatry 60: 24-28.

Supplementary Information accompanies the paper on the Neuropsychopharmacology website (http://www.nature.com/npp) 